\title{
Avaliação da qualidade da tilápia do Nilo (Oreochromis niloticus) cultivada, eviscerada e estocada em gelo
}

\section{Evaluation of quality of Nile tilapia (Oreochromis niloticus) cultivation, eviscerated and stored in ice}

\author{
Tatiana Pacheco Rodrigues, ${ }^{*}$ Mônica Queiroz de Freitas, ${ }^{* *}$ Eliane Teixeira Mársico, ${ }^{* *}$ Robson Maia Franco, ${ }^{* *}$ \\ Silvia Conceição Reis Pereira Mello, ${ }^{*}$ Ivone Costa, ${ }^{* * *}$ Nathália de Oliveira Zúniga ${ }^{* * *}$
}

\begin{abstract}
Resumo
O objetivo desta pesquisa foi avaliar a qualidade da espécie de peixe tilápia do Nilo (Oreochromis niloticus), cultivada, eviscerada e estocada em gelo, associando análises sensoriais, físico-químicas e bacteriológicas. A análise sensorial consistiu de Teste de Aceitação com julgadores não treinados em amostras cozidas de peixes estocados por 1 a 15 dias. Foram realizadas contagens de bactérias heterotróficas aeróbias mesófilas e pH em amostras, com e sem pele, estocadas por 28 dias, além da determinação das bases voláteis totais (BVT), trimetilamina (TMA) e óxido de trimetilamina (OTMA) em amostras estocadas por 22 dias. As análises de BVT e TMA apresentaram-se dentro dos limites legais durante os 22 dias de estocagem, enquanto as contagens bacteriológicas estiveram dentro de limites aceitáveis até o $18^{\circ}$ dia de estocagem. Com base nos resultados deste experimento, sugere-se o prazo de vida comercial de 15 a 18 dias para tilápia cultivada, eviscerada e estocada em gelo.
\end{abstract}

Palavras-chave: tilápia do Nilo, Oreochromis niloticus, qualidade.

\begin{abstract}
The objective of this research was to evaluate the quality of the specie of fish Nile tilapia (Oreochromis niloticus), cultivation, eviscerated and stored in ice, involving sensory analysis, physical-chemical and bacteriological analyses. The sensory analysis consisted of Acceptance Test with painelists not trained in samples of cooked fish stocked by 01 to 15 days. We performed mesophilic aerobic count and $\mathrm{pH}$ in samples with and without skin stored for 28 days, in addition to determining the volatile total bases (BVT), trimethylamine (TMA) and trimethylamine oxide (TMAO) in samples stored for 22 days. Analyses of BVT and TMA showed up within the legal limits during the 22 days of storage, while the bacterial counts were within acceptable limits until the 18 th day of storage. Based on the results of this experiment, it is suggested the period of commercial life of 15 to 18 days for tilapia cultivation, eviscerated and stored in ice.
\end{abstract}

Keywords: Nile tilapia, Oreochronis niloticus, quality.

\section{Introdução}

Nas últimas décadas, com a pesca predatória indiscriminada e o decréscimo dos cardumes comerciais, o cultivo planejado de peixes de água doce começou a se destacar na agroindústria brasileira. Neste contexto, a tilápia do Nilo (Oreochromis niloticus) é uma espécie reconhecidamente importante para a aqüicultura, em função do grande potencial de produção que apresenta (Vieira et al., 2001). Segundo dados do Instituto Brasileiro do Meio Ambiente e dos Recursos Naturais Renováveis (IBAMA), a produção de tilápias no Brasil em 2004 foi de 69.078 toneladas (Brasil, 2005).

Geralmente, o termo qualidade refere-se à aparência estética e frescor, ou ao grau de deterioração que o pescado sofreu. Também pode estar relacionado com aspectos de segurança, como: ausência de bactérias patogênicas, parasitas ou compostos químicos. A qualidade do pescado fresco pode ser avaliada por análises sensoriais, químicas e microbiológicas. Os métodos para a avaliação da qualidade do pescado fresco podem ser convenientemente divididos em duas categorias: sensorial e instrumental. Dado que o consumidor é o último juiz da qualidade, a maioria dos métodos químicos ou instrumentais deve ser correlacionada com a avaliação sensorial, de forma científica e sob condições controladas (Huss, 1998).

O Teste de Aceitação é um teste sensorial subjetivo; portanto, as respostas são inteiramente pessoais ou hedônicas, já que são relativas ao prazer ou graus dele. As determinações subjetivas, onde a resposta está baseada nas preferências do julgador por um produto, podem ocorrer em trabalhos de

\footnotetext{
* Doutora em Medicina Veterinária. E-mail: tatipr.br@bol.com.br

** Professor do Departamento de Tecnologia dos Alimentos - UFF

*** Aluno do Curso de Especialização em Irradiação de Alimentos - UFF.

**** Aluno do Curso de Graduação em Medicina Veterinária - UFF
} 
campo, como investigações de mercado e desenvolvimento de novos produtos, onde se necessita da reação do consumidor (Meilgaard et al., 1991).

No Brasil, as características do peixe fresco considerado próprio para consumo são determinadas por legislação como no Regulamento da Inspeção Industrial e Sanitária de Produtos de Origem Animal (RIISPOA) - art. 442 (Brasil, 1997a), na Portaria nº 185 do Ministério da Agricultura (Brasil, 1997b) e por normas como as da Associação Brasileira de Normas Técnicas (ABNT, 1993). Todavia, critérios de avaliação para cada espécie de peixe não estão definidos. Portanto, os objetivos desta pesquisa foram: realizar Teste de Aceitação com julgadores não treinados, utilizando escala hedônica, após o peixe em estudo ser estocado em gelo nos períodos de 1, 8 e 15 dias; contagem de bactérias heterotróficas aeróbias mesófilas, nos períodos de estocagem em gelo de 1, 4, 8, 11, 15, 18, 22 e 28 dias; além de determinar o $\mathrm{pH}$ nos períodos de estocagem de 1, 4, 8, 11, 15, 18, 22 e 28 dias; a produção de bases voláteis totais (BVT), trimetilamina (TMA) e óxido de trimetilamina (OTMA), após estocagem em gelo por 1, 4, 8, 11, 15, 18 e 22 dias.

\section{Material e métodos}

\section{Obtenção e estocagem das amostras}

As tilápias foram obtidas em duas pisciculturas municipais do Estado do Rio de Janeiro, Brasil. Foram coletados 135 machos revertidos, com idade entre 4 e 6 meses e peso médio de $412,1 \mathrm{~g}$ (total de 55,6kg), no período de agosto de 2005 a setembro de 2006. Após 24 horas de depuração, os peixes foram capturados, receberam choque térmico com gelo, foram eviscerados manualmente e lavados; em seguida, acondicionados em caixas isotérmicas contendo gelo, na proporção de $1 \mathrm{~kg}$ de gelo para $1 \mathrm{~kg}$ de peixe e levados até o Departamento de Tecnologia dos Alimentos da Universidade Federal Fluminense. Após a chegada no laboratório, os peixes foram acondicionados em recipientes contendo gelo, na proporção de $1 \mathrm{~kg}$ de gelo para $2 \mathrm{~kg}$ de peixe e em seguida estocados e mantidos em refrigerador doméstico à temperatura de $0,3^{\circ} \mathrm{C} \pm 0,35$, até o momento de sua utilização para as análises sensoriais, bacteriológicas e físico-químicas.

\section{Teste de aceitação}

Duzentos e quarenta consumidores do produto (julgadores não treinados), compostos por 157 mulheres e 83 homens com idades entre 18 e 61 anos, participaram da análise utilizando ficha contendo uma escala hedônica com extremos de 1 a 9 , onde 1 correspondia a desgostei muitíssimo e 9 representava gostei muitíssimo, conforme metodologia descrita por Stone e Sidel (1993). Foram utilizadas amostras cozidas de peixes previamente estocadas em gelo por 1, 8 e 15 dias. Para esta análise foram utilizados $13,8 \mathrm{~kg}$ de peixe (peso médio de 576,4g).

\section{Análises físico-químicas}

Para as análises físico-químicas foram utilizados 11 exemplares de tilápia do Nilo com peso médio de 376,3 g. As análises consistiram na determinação do pH nos dias 1, 4, 8, 11, 15, 18, 22 e 28 de estocagem; quantificação de bases voláteis totais (BVT), de trimetilamina (TMA) e de óxido de trimetilamina (OTMA), que foram realizadas nos dias 1, 4, 8, 11, 15, 18 e 22 de estocagem. Para avaliação do potencial hidrogeniônico $(\mathrm{pH})$, foi utilizado o método potenciométrico conforme Brasil (1981). Para a quantificação de bases voláteis totais (BVT) e trimetilamina (TMA), foi utilizado o método da placa de microdifusão de Conway, conforme Brasil (1981). A determinação do OTMA foi realizada segundo a técnica descrita por Yamagata et al. (1969), utilizando as modificações sugeridas por Parkin e Hulting (1982).

\section{Contagem de bactérias heterotróficas mesófilas}

Para as análises bacteriológicas foram utilizados 11 exemplares de tilápia do Nilo com peso médio de $376,3 \mathrm{~g}$. As análises foram realizadas nos dias 1, 4, 8, 11, 15, 18, 22 e 28 de estocagem em amostras de músculo com e sem pele. A metodologia utilizada para realizar a contagem de bactérias heterotróficas aeróbias mesófilas foi baseada em Morton (2001) com algumas adaptações.

\section{Análises estatísticas}

Para os resultados sensoriais foi utilizada a análise de variância e teste de comparação entre médias. Além disso, foram procedidas análises de regressão nos resultados físico-químicos e bacteriológicos, em que a variável independente foi o tempo de estocagem do pescado. Todas as análises estatísticas foram realizadas no programa Statistical Analytical System (SAS, 1999).

\section{Resultados e discussão}

\section{Teste de aceitação}

Os resultados do Teste de Aceitação estão dispostos na Tabela 1. Nota-se, pelos resultados médios, que não houve diferença significativa $(p>0,05)$ nos três períodos de estocagem analisados, demonstrando que os julgadores consideraram as três amostras aptas para consumo, pois os escores médios ficaram próximos de 8, que corresponde a "gostei muito". Assim, segundo os consumidores, o peixe em estudo obteve uma boa aceitação até 15 dias de estocagem.

Tabela 1: Médias $(\bar{X})$ e desvio-padrão $\left(s_{x}\right)$ dos escores resultantes do Teste de Aceitação em escala hedônica de nove pontos, de tilápia do Nilo (Oreochromis niloticus) cultivada, eviscerada e estocada em gelo durante 15 dias.

\begin{tabular}{c|c}
\hline Período de estocagem & Escore $\left(\overline{\mathrm{X}}_{ \pm \mathrm{sx}}\right)$ \\
\hline 1 dia & $8,08^{\mathrm{a}}( \pm 0,82)$ \\
8 dias & $7,93^{\mathrm{a}}( \pm 0,99)$ \\
15 dias & $7,83^{\mathrm{a}}( \pm 1,12)$ \\
\hline
\end{tabular}

a Médias na mesma coluna seguidas de letras iguais, não diferem significativamente $(p>0,05)$.

\section{Potencial hidrogeniônico $(\mathrm{pH})$}

As amostras com pele, assim como as sem pele, encontraram-se dentro dos padrões legais vigentes até o 18응 dia (Brasil, 1997a) [Figura 1]. 


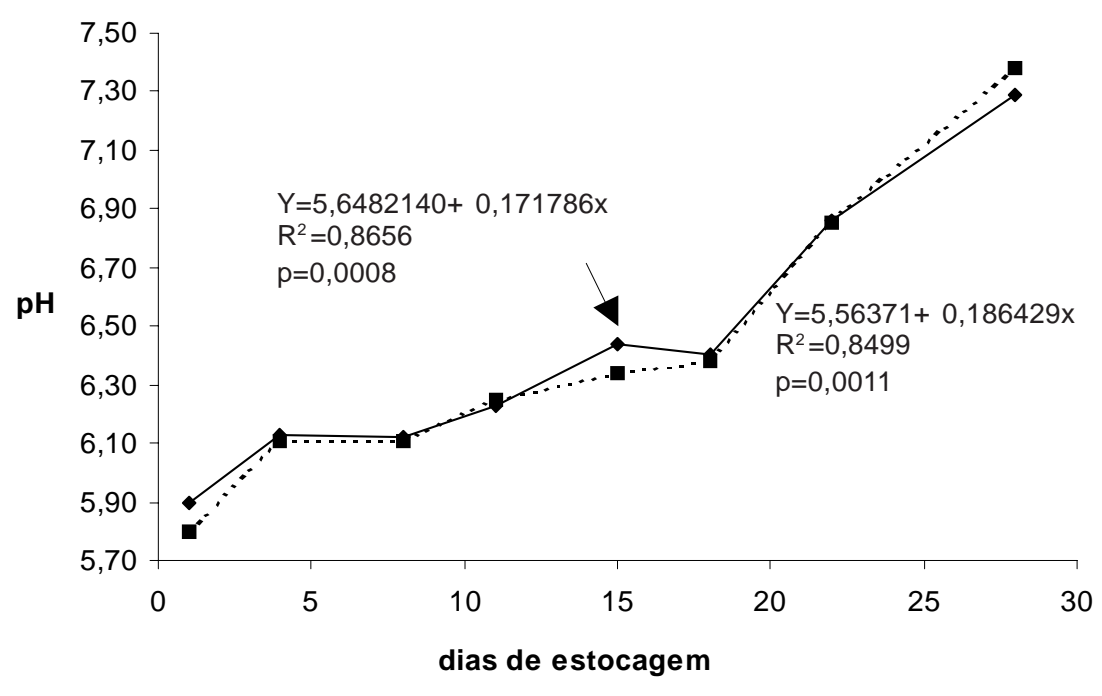

$\multimap-$ MÚSCULO COM PELE .... - . - MÚSCULO SEM PELE

Figura 1: Resultados da determinação do potencial hidrogeniônico $(\mathrm{pH})$ de tilápia do Nilo (Oreochromis niloticus) cultivada, eviscerada e estocada em gelo por 28 dias.

limites aceitáveis pela legislação, de $30 \mathrm{mg}$ de N/100g de carne (Brasil, 1997a). Algo semelhante ocorreu em outros experimentos com tilápia do Nilo. Guimarães et al. (1988); Sales et al. (1988); Elisabetta et al. (2001); Soccol (2002); Albuquerque et al. (2004) observaram baixos valores de BVT quando os peixes foram rejeitados sensorialmente, demonstrando a necessidade de uma reavaliação do limite aceitável deste parâmetro legal para esta espécie.

Nota-se que a partir do quarto dia de estocagem houve um aumento mais evidente no valor de BVT, assim como o de $\mathrm{pH}$, demonstrando o efeito dos eventos bioquímicos que depreciam a qualidade nas etapas iniciais de armazenagem, enquanto as bactérias ainda apresentavam baixas contagens, pois os metabólitos destas somente seriam responsáveis, segundo Contreras-Guzmán (1994), numa segunda fase, pela alteração do frescor do pescado.

Niizeki et al. (2002) observaram um valor

Observando os resultados obtidos por outros autores, estes diferem dos encontrados neste experimento. No trabalho realizado por Guimarães et al. (1988), a partir do 11으 dia de estocagem, o $\mathrm{pH}$ estava acima do permitido $(6,9)$. Sales et al. (1988), assim como Siqueira (2001), observaram que desde o primeiro dia de estocagem os valores de $\mathrm{pH}$ encontravamse fora dos limites, respectivamente 6,7 e 6,6. Soccol (2002) observou que o $\mathrm{pH}$ ficou fora dos parâmetros a partir do $13^{\circ}$ dia de estocagem $(6,6)$. No experimento de Zúniga et al. (2005), o valor de $\mathrm{pH}$ somente ultrapassou o permitido pela legislação no $21^{\circ}$ dia de armazenamento $(6,9)$.

Os diferentes resultados de $\mathrm{pH}$ observados nos experimentos devem-se, provavelmente, aos diversos fatores que, segundo Huss (1998), influenciam na glicólise post mortem e, conseqüentemente, no $\mathrm{pH}$; entre estes, a espécie de pescado, o estado nutricional do peixe, a quantidade e grau de esgotamento no momento da morte.

Ao final do período de estocagem, os valores de $\mathrm{pH}$ encontraram-se próximos da neutralidade. Isto pode ter ocorrido, segundo Contreras-Guzmán (1994), devido à presença de catabólitos, como amônia, originados da atividade bacteriana sobre os aminoácidos da carne.

\section{Bases voláteis totais, trimetilamina e óxido de trimetilamina}

Nos resultados obtidos nesta pesquisa nota-se que, durante a estocagem (Figura 2), o valor de BVT não ultrapassou os basal de OTMA de $11,25 \mathrm{mg} \mathrm{N}$, mas estes utilizaram cromatografia para realizar a análise, enquanto, neste experimento, utilizou-se o método de Microdifusão de Conway. O valor de 15,93mg N OTMA observado no primeiro dia de estocagem difere do citado por Contreras-Guzmán (1994), onde a tilápia do Nilo possuiria teores intermediários de OTMA entre 25 e $100 \mathrm{mg} \mathrm{N}$.

Quanto ao valor de TMA, observou-se que, durante a estocagem, este não ultrapassou o valor preconizado pela legislação (BRASIL, 1997a). Já para o OTMA não há parâmetros até o momento na legislação para serem comparados.

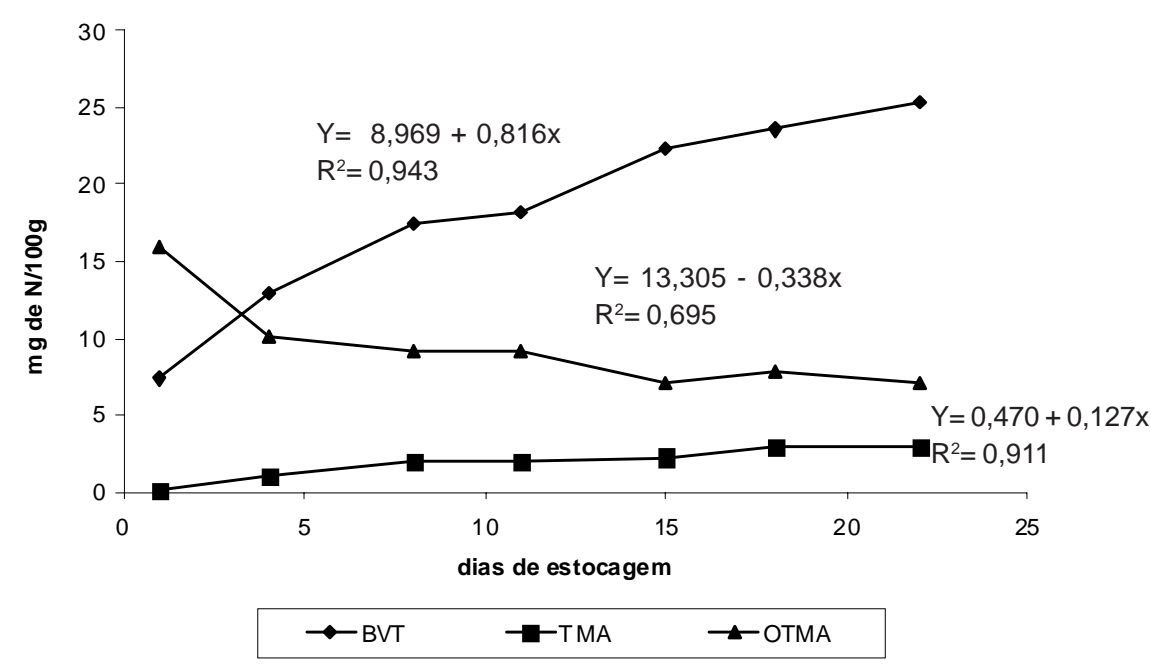

Figura 2: Resultados da produção de bases voláteis totais (BVT), de óxido de trimetilamina (OTMA) e trimetilamina (TMA) de tilápia do Nilo (Oreochromis niloticus) cultivada, eviscerada e estocada em gelo por 22 dias. 


\section{Contagem de bactérias heterotróficas mesófilas}

As bactérias mesófilas alcançaram a fase de crescimento exponencial (Figura 3) na amostra com pele no $22^{\circ}$ dia de estocagem $(7,60 \mathrm{log})$ e na amostra sem pele no $28^{\circ}$ dia $(5,20$ log). A contagem de bactérias mesófilas estava dentro dos limites recomendados pela ICMSF (1986) de $10^{7} \mathrm{UFC} / \mathrm{g}$ para contagem total de aeróbios, até o $18^{\circ}$ dia de estocagem na amostra com pele e no $28^{\circ}$ dia na amostra sem pele.

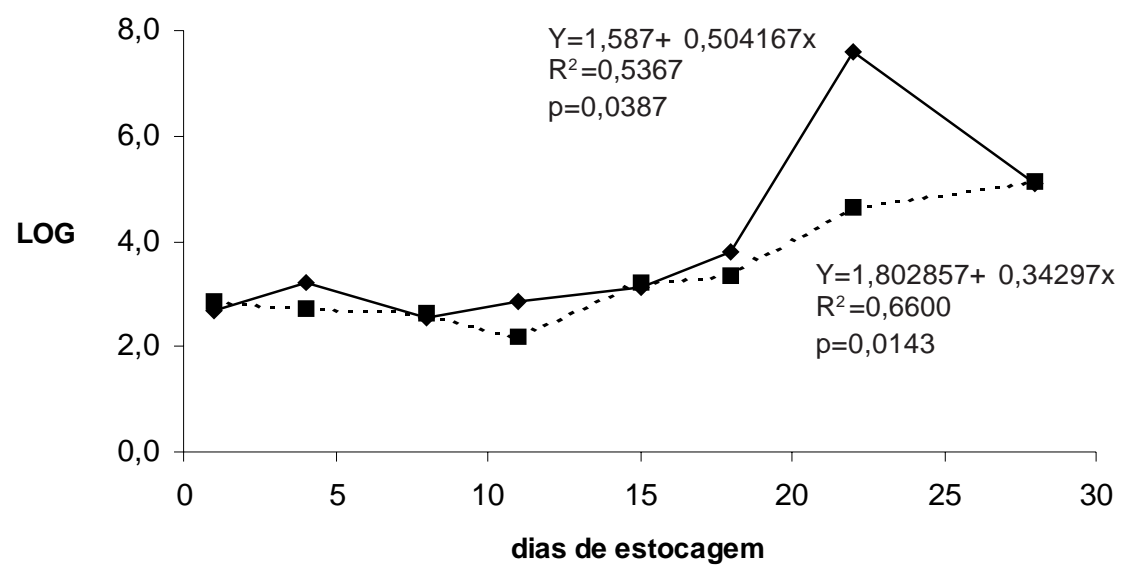

$\longrightarrow$ MÚSCULO COM PELE ..... . . MÚSCULO SEM PELE

Figura 3: Resultados em logaritmo da contagem de bactérias heterotróficas aeróbias mesófilas de tilápia do Nilo (Oreochromis niloticus) cultivada, eviscerada e estocada em gelo por 28 dias
De acordo com o descrito por Huss (1997), pode-se considerar que a tilápia foi mantida em boas condições de armazenagem, já que os resultados das contagens não ultrapassaram os limites aceitáveis até 0220 dia de estocagem, demonstrando também as boas condições sanitárias em que os peixes foram manipulados e mantidos.

Os resultados deste experimento são próximos aos observados por Zúniga et al. (2005), que obtiveram contagens semelhantes, exceto pela fase log da musculatura sem pele, que ocorreu no $20^{\circ}$ dia de estocagem $(7,114 \log$ UFC/g), enquanto neste experimento ocorreu no $28^{\circ}$ dia. Nos resultados obtidos por Pullela et al. (1998) e Martins, Vaz e Minozzo (2002) observou-se que as contagens em tilápias recém-capturadas já apresentavam contagens acima de 3,0 log, devido provavelmente à contaminação do ambiente do qual as amostras foram retiradas.

\section{Conclusão}

Com base nos resultados deste experimento, sugere-se o prazo de validade comercial de 15 a 18 dias para tilápia cultivada, eviscerada e estocada em gelo.

\section{Referências}

ABNT. Associação Brasileira de Normas Técnicas. Normas ABNTDefinições das etapas básicas dos fluxos de operações em estabelecimentos produtores/fornecedores de alimentos. NBR 12806/ 93. 1993.

ALBUQUERQUE, W.F., ZAPATA, J.F.F., ALMEIDA, R.S. Estado de frescor, textura e composição muscular da tilápia do Nilo (Oreochromis niloticus) abatida com dióxido de carbono e armazenada em gelo. Revista Ciência Agronômica, v. 35, número especial, p. 264-271, 2004.

BRASIL. Ministério da Agricultura. Secretaria Nacional de Defesa Agropecuária. Laboratório Nacional de Referência Animal. Métodos analíticos oficiais para controle de produtos de origem animal e seus ingredientes: II-Métodos físicos e químicos. Brasília, DF, 1981.

Ministério da Agricultura e do Abastecimento. Secretaria Nacional de Defesa Agropecuária. Lei n 30691, de 29/03/52. Regulamento da Inspeção Industrial e Sanitária de Produtos de Origem Animal. Brasília, DF, 1997a.

Ministério da Agricultura e do Abastecimento. Secretaria

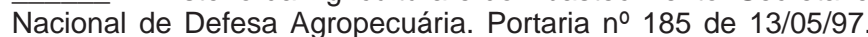
Regulamento Técnico de Identidade e Qualidade de Peixe Fresco (Inteiro e Eviscerado). Brasília, DF, 1997b.

Ministério do Meio Ambiente. Instituto Brasileiro do Meio Ambiente e dos Recursos Naturais Renováveis. Estatística da pesca - Brasil 2004 - Grandes regiões e unidades da federação. Brasília, DF, 2005. <Disponível em http://www.presidencia.gov.br> Acesso em 20 de jan de 2008.

CONTRERAS-GUZMÁN, E. S. Bioquímica de pescados e derivados. Jaboticabal: FUNEP, 1994, $409 \mathrm{p}$.
ELISABETTA, T. et al. Efecto del tiempo de retardo en la refrigeración sobre la frescura de la Tilapia (Oreochromis spp) cultivada. Anales Venezolanos de Nutrición, v. 14, n. 1, p. 3-8, 2001.

GUIMARÃES O. J.; SALES, R. O.; MONTEIRO, J. C. S. Análise química, microbiológica e organoléptica da tilápia do Nilo (Sarotherodon nilotic), conservada em gelo. Ciência Agronômica, v. 19, n. 1, p. 147-151, 1988. HUSS, H. H. Garantia da qualidade dos productos da pesca. FAOOrganização das Nações Unidas para Agricultura e Alimentação Documento técnico sobre as pescas 334. Roma, 1997, 176 p.

HUSS, H. H. El pescado fresco: su calidad y cambios de su calidad. FAO - Organização das Nações Unidas para Agricultura e Alimentação - Documento tecnico de pesca 348. Roma, 1998. 202 p.

ICMSF. Iternational Commission on Microbial Specifications for Foods. Microorganisms in foods.2. Sampling for microbiological analysis: Principles and specific applications. 2. ed. Blackwell Scientific Publications, 1986.

MARTINS, C. V. B. ; VAZ, S. K.; MINOZZO, M. G. Aspectos sanitários de pescados comercializados em "pesque-pagues" de Toledo (PR). Higiene Alimentar, v. 16, p. 51-56, 2002.

MEILGAARD, G.; CIVILLE, V.; CARR, B.T. Sensory evaluation techniques. 2. ed., CRC Press. Boca Ratón, 1991.

MORTON, R. D. Aerobic Plate Count. In: APHA. American Public Health Association. Compendium of methods for the microbiological examination of foods. 4. ed. APHA: Washington-DC. Cap. 7, p. 63-67, 2001.

NIIZEKI, N. et al. Mechanism of biosyntesis of trimethylamine oxide from choline in the teleost tilapia, Oreochromis niloticus, under freshwater conditions. Comp. Biochem. Physiol. v.131B, p. 371-386, 2002. 
OGAWA, M.; MAIA, E. L. Manual de pesca. São Paulo: Varela, 1999, p. 175-187.

PARKIN, K. L.; HULTING, H. O. Some facts influencing the prodution of dimethylamine and formaldehyde in minced and intact red hake muscle. Journal of Food Processing and Preservation, v. 6, p. 73-97, 1982.

PULLELA, S., et al. Indicative and pathogenic microbiological quality of aquacultured finfish grown in different production system. Journal of Food Protection, v. 61, n. 2. p. 205-210, 1998.

SALES, R. O. et al. Avaliação do estado de frescor do pescado capturado em água doce e mantido sob refrigeração, no açude de Orós, Ceará. Ciência Agronômica, v. 19, n. 2, p. 109-115, 1988.

SAS Institute. SAS User's Guide. 6.04 Edition. SAS Institute Inc., Cary, NC.1999.

SIQUEIRA, A. A. C. Z. Efeito da irradiação e refrigeração na qualidade e no valor nutritivo da tilápia (Oreochromis niloticus). Piracicaba, 2001. 154 f. Dissertação (Mestrado em Ciência e Tecnologia de Alimentos), Universidade de São Paulo, Piracicaba, 2001.

SOCCOL, M. C. H. Otimização da vida útil da tilápia cultivada (Oreochromis niloticus), minimamente processada e armazenada sob refrigeração. Piracicaba, 2002. 141 f. Dissertação (Mestrado em Ciência e Tecnologia de Alimentos), Universidade de São Paulo, Piracicaba, 2002.
STONE, H., SIDEL, J. L. Sensory evaluation pratice. 2. ed., Academic Press: San Diego, 1993. 337 p.

VIEIRA, I., CYRINO, P. E. J., PEZZANATO, E. L. Colina e betaína em rações purificadas na nutrição da tilápia do Nilo (Oreochromis niloticus). Scientia Agricola, v. 58, n. 4, 2001. <Disponível em http:// www.scielo.br > Acesso em 8 de nov. de 2003.

YAMAGATA, M.; HORIMOTO, K.; NAGAOKA, C. Assessement of green tuna: determining Trimethylamine Oxide and its distribution in tuna muscles. Journal of Food Science, v. 34, p. 156-159, 1969.

ZÚNIGA, N. O. C., et al. Determinação do prazo comercial da tilápia (Oreochromis niloticus) eviscerada e estocada à temperatura de $0^{\circ} \mathrm{C}$ com base na contagem de bactérias heterotróficas aeróbias mesófilas e determinação de pH. VIII Congresso Brasileiro de Higienistas de Alimentos - 12 a 15.04.2005-CD. 